\title{
O TECNICISMO/TAREFISMO NOS CURSOS DE FORMAÇÃO PROFISSIONAL EM EDUCAÇÃO FÍSICA: ALGUMAS REFLEXÕES
}

\author{
THE TECHNIQUE/TASK IN PROFESSIONAL TRAINING COURSES \\ IN PHYSICAL EDUCATION: SOME REFLECTIONS
}

\section{EL TECNICISMO/TAREFISMO EN LOS CURSOS DE FORMACIÓN PROFESIONAL EN EDUCACIÓN FÍSICA: ALGUNAS REFLEXIONES}

Marcelo de Farias Teixeira ${ }^{1}$ Universidade Metodista de Piracicaba (UNIMEP), Piracicaba/SP - Brasil ${ }^{1}$

\begin{abstract}
Resumo O objetivo do artigo é analisar e realizar reflexões sobre o tecnicismo/tarefismo nos cursos de formação profissional em Educação Física. Como pano de fundo abordamos a história da influência militar na área e um olhar crítico acerca do influxo de ex-atletas, destaca-se também as maiores contradições cometidas dentro da temática. O método utilizado foi o dedutivo, com pesquisa bibliográfica em livros de sociologia, antropologia, história, esportes, lazer e política. Conclui-se que de fato o tecnicismo e o tarefismo se apresentam como um grande problema a ser enfrentado não só pela graduação dos cursos de Educação Física das universidades que ofertam as disciplinas de lazer e esporte escolar, mas também isso acaba se estendendo aos programas de pós-graduação, o que tende a complicar ainda mais a situação, pois esse é o local onde justamente deveria haver uma maior aproximação e diálogo entre as duas vertentes da Educação Física, seja o da performance/ biodinâmica ou da cultura e práticas corporais.
\end{abstract}

Palavras-chave: Tecnicismo; Tarefismo; Educação Física.

Abstract The objective of this article is to analyze and to make reflections about technicalism/task in the courses of professional formation in Physical Education. As background, we approach the history of military influence in the area and a critical look at the influx of former athletes and highlights the major misconceptions committed within the thematic. The method used was the deductive, with bibliographical research in books of sociology, 
anthropology, history, sports, leisure and politics. It is concluded that, in fact, technicalism and task are presented as a great problem to be faced not only by the graduation of the Physical Education courses offered by the universities that offer the subjects of leisure and school sports, but also, this extends to the programs of post which tends to complicate the situation further, since this is the place where there should be a closer approximation and dialogue between the two aspects of Physical Education, be it performance/biodynamics. Keywords: Technicality; Task; Physical Education.

Resumem El objetivo del artículo es analizar y realizar reflexiones sobre el tecnicismo/tarefismo en los cursos de formación profesional en Educación Física. Como telón de fondo, abordamos la historia de la influencia militar en el área y una mirada crítica sobre el influjo de ex atletas se destaca también los mayores equívocos cometidos dentro de la temática. El método utilizado fue el deductivo, con investigación bibliográfica en libros de sociología, antropología, historia, deportes, ocio y política. Se concluye que de hecho el tecnicismo y tarefismo se presentan como un gran problema a ser enfrentado no sólo por la graduación de los cursos de Educación Física de las universidades que ofrecen las disciplinas de ocio y deporte escolar, pero también eso acaba extendiéndose a los programas de post-graduación que es el lugar donde justamente debería haber una mayor aproximación y diálogo entre las dos vertientes de la Educación Física, sea el de la performance/biodinámica.

Palabras clave: Tecnicismo; Tarefismo; Educación Física.

\section{INTRODUÇÃo}

O objetivo do texto é analisar e realizar reflexões sobre o tecnicismo/tarefismo nos cursos de formação profissional em Educação Física. A história da influência militar na área e um olhar crítico sobre o influxo de ex-atletas serão apresentados como um dos pontos chave, destaca-se também os maiores equívocos cometidos dentro da temática. Trata-se de um ensaio realizado por meio da pesquisa bibliográfica de método dedutivo efetuada em artigos, livros de sociologia, antropologia, educação, esportes, lazer e política em bibliotecas da Unimep, Unimontes e UFsCar. A utilização das referidas instituições se deu por conveniência de localização e pela oferta de um maior acervo sobre a temática. Neste estudo, apesar da abordagem das origens históricas, todos os autores selecionados são contemporâneos, com exceção do autor clássico Jofre Dumazedier, considerado precursor no tema lazer e que serviu de referência para os autores brasileiros. O período compreendido dos artigos e livros analisados datam da década de 1980 citada, período em que o debate acadêmico na área de Educação Física foi intensificado, havendo diferentes abordagens questionando o modelo de Educação Física tradicional e militar, ainda que a aula dessa disciplina escolar continuasse tendo forte ênfase nos aspectos técnicos e na aptidão física.

É importante esclarecer que o debate acadêmico da área de Educação Física que se intensificou a partir do final da década de 1970 reflete a composição epistemológica da

Comunicações $\mid$ Piracicaba $\mid$ v. $26 \mid$ n. $1 \mid$ p. 297-308| jan.-abr. 2019 
área, com origem nos estudos pedagógicos e humanistas, mas marcada também pela cientificidade dos estudos biológicos, tendo como intuito disciplinar o corpo e tornar os sujeitos fortes e saudáveis, de acordo com as influências europeias do final do século XVIII e que se intensificaram ao longo do século XIX (SOARES, 1994).

O tarefismo e o tecnicismo que têm influenciado certos cursos superiores de Educação Física, estão relacionados principalmente com as disciplinas de lazer e esportes da grade curricular ofertadas no curso de graduação tanto no bacharelado como na licenciatura. $\mathrm{O}$ sentido que aqui tratamos de tarefismo e tecnicismo é de práticas pedagógicas que muitas vezes é desprovida de reflexão. O problema é que o curso já atrai como clientela de alunos uma quantidade significativa de ex-atletas que tendem a reproduzir basicamente o que aprenderam durante sua jornada esportiva. Somando-se a isso, os alunos que recebem hoje essa transmissão de tarefismo e tecnicismo tendem a ser futuros professores que irão dar sequência a esse ciclo, como aponta Cunha (1988, p. 81), ao salientar que:

[...] a principal influência no comportamento do professor é sua própria história como aluno e que, para além das teorias pedagógicas que ele aprende, o que marca seu comportamento são as práticas de seus antigos professores.

Nesse sentido, na intenção de promover uma relação com a autora mencionada, vamos nos ater aqui, sobretudo na parte da citação em que ela destaca que o que marca o comportamento de um professor - no caso, recém-formado - são de fato as práticas dos seus antigos mestres. Talvez se possa dizer que essa situação é fundamentalmente a raiz do problema a ser discutido aqui, pois os gregos já diziam que a história é cíclica e não linear, desse modo, quando o ex-atleta ingressa no curso superior em Educação Física, há nítida carência de bagagem acadêmica e excesso de conhecimento proveniente do senso comum que lhe é referência e também do "fazer por fazer". Sendo assim irá se juntar aos colegas que - apesar de não serem ex-atletas - irão receber também a transmissão do dito tarefismo e tecnicismo de professores de alguns dos principais componentes curriculares da graduação.

Por fim, é importante que se faça uma alusão no sentido de que uma das origens dessa área tem um forte viés militar, o que possivelmente contribuiu de forma significativa para que se inserisse ali toda a questão disciplinar disseminada pelo militarismo, mas que também estava extremamente associada a uma técnica desportiva e ginástica apuradas; nessa sequência, vale ressaltar que esses eram os valores ideológicos dos quais o Estado, no contexto do Brasil, até a década de 1970, se utilizava da premissa que um país precisaria ter corpos fortes e saudáveis para que assim também tivesse um exército vigoroso para defender a nação como aponta Silva (2010, p. 147):

Na década de 1970, o governo militar investiu na educação física em decorrência de diretrizes pautadas no nacionalismo, na integração e na segurança nacional. Como exemplo dessa hegemonia tecnicista e desse interesse pelo desenvolvimento do campo, podemos afirmar que a educação física, o esporte e o lazer inseriram-se no contexto universitário e passaram a receber maiores atenções por parte do Ministério da Educação. 
Nesse sentido, se percebe claramente que a ênfase era voltada para a aptidão física estando em grande aproximação com o campo esportivo, em detrimento do caráter pedagógico. Na década de 1930, foram elaborados os primeiros currículos da área com o surgimento da Escola de Educação Física do Rio de Janeiro e, também, do então Centro Militar de Educação Física - CMEF, que apesar de ter sido fundado em 1922, transformou-se em Escola de Educação Física do Exército somente na década de 1930 (TAFFAREL, 1993).

Esses currículos acabaram tendo como efeito um projeto piloto, que seria adotado pelas demais instituições que vieram a surgir no país e tinha como principal característica a "formação curta, dois anos, e enfatizava a técnica desportiva e os aspectos médicos, militares e higienistas presentes no cenário nacional" (ISAYAMA, 2003, p. 12). Contudo, fica compreensível entender que a forte ligação da Educação Física com o tecnicismo e o tarefismo teve como origem e influência a arraigada tradição militar, e como consequência, apesar dos avanços significativos da área, enfrenta até hoje inúmeras dificuldades para o rompimento com essa abordagem.

Podemos citar como um clássico exemplo disso os ditos "manuais esportivos e de recreação" que não raro pode-se encontrar em qualquer biblioteca de universidade que contemple o curso de Educação Física. Esses livros (recreação 1000 exercícios, handebol 1000 exercícios, futsal 1000 exercícios, voleibol 1000 exercícios etc.) funcionam como verdadeiros guias práticos e dessa forma sugerem que qualquer pessoa poderia ministrar uma aula de Educação Física cujo tema fossem esses conteúdos esportivos/recreativos. É oportuno também salientar que existem docentes da graduação em Educação Física que transformam suas aulas em verdadeiros treinamentos esportivos que visam ao aluno atingir à perfeição técnica e tática de determinada modalidade, o que só faz aumentar o entendimento de que "para ser um bom professor da área é necessário ter aptidão física e gesto técnico esportivo apurado". É válido ressaltar que alguns fatos inusitados são adequados para ilustrar o sólido emparelhamento da área à aptidão física e ao exímio gesto técnico, por exemplo, o título de professor de educação física conferido pela então Secretaria de Educação e Assistência Pública do Estado da Bahia ao mestre de capoeira Manuel dos Reis Machado, mais conhecido como "mestre bimba" na década de 1930, coincidentemente na mesma época da criação da Escola de Educação Física do Exército, o mestre bimba inclusive ministrou treinamento de capoeira aos militares na ocasião. Nesse sentido, também pode-se encontrar situações semelhantes na Educação Física Escolar contemporânea, por exemplo, a ideia no censo comum de que todo professor da área deve obrigatoriamente ter um corpo atlético, ser extrovertido e saber jogar bem todas as modalidades esportivas.

\section{O "FAZER POR FAZER..."}

Para efeito de esclarecimento, talvez seria importante considerarmos aqui a semelhança entre tecnicismo e tarefismo: pois bem, o dito tecnicismo pedagógico inspirado na teoria behaviorista em que, segundo Saviani (1995, p. 15), "Buscou-se planejar a educação 
de modo a dotá-la de uma organização racional [...]. Para tanto, era mister operacionalizar os objetivos e, pelo menos em certos aspectos, mecanizar o processo". Assim sendo, e dentro dessa perspectiva, percebe-se que não há muito espaço para a reflexão e a criticidade instigadas pelo professor e desenvolvida pelo aluno dadas as atividades extremamente mecânicas alinhadas à organização racional dos meios que visavam adequação à produção capitalista. Já o "tarefismo" de que fala Marcellino (2010) está relacionado com a crítica que esse autor faz a respeito do processo de formação dos profissionais do lazer, que está, assim como o tecnicismo, desprovido de reflexão, criticidade e confinado em um fazer por fazer. Nesse sentido, Marcellino (IBIDEM, p. 62), ainda afirma que:

Desconhecendo a teoria do lazer, o profissional de educação física que atua nessa área, além de confundir a prática do lazer com a prática profissional que o lazer requer, não estabelece uma prática, mas sim um "tarefismo". Isso pode ser verificado nas aulas de graduação de muitos cursos superiores e nos "manuais" de recreação e lazer.

Como vimos, o autor alerta para os muitos equívocos que ainda infelizmente acontecem na graduação em Educação Física, em que muitos professores tendem a confinar as aulas das referidas disciplinas em apenas simples reproduções de atividades desprovidas de reflexão e, às vezes, tendo como fonte os manuais de recreação e lazer que contêm "mil exercícios". Sendo assim, no que se refere especificamente à disciplina de recreação/lazer, o futuro profissional que se forma tende a reproduzir todas essas atividades, com fim em si mesmas, contribuindo ainda mais para o histórico preconceituoso da área em que, para o senso comum, o lazer se resume apenas em atividades recreativas desenvolvidas por monitores, tendo como característica uma condição supérflua. Essas ideias vão ao encontro das discussões de Ferreira et al. (2013) sobre a visão funcionalista do lazer e o especialista "tradicional" que atua em tal campo.

Já com relação às disciplinas de esportes, o que se pode dizer é que o recém-formado em licenciatura, por exemplo, possivelmente conduzirá uma práxis pedagógica sem relação ou pelo menos de forma muito limitada com os aspectos sociais do esporte escolar e das comunidades, pois esse professor - impregnado do tecnicismo acadêmico - estará, de fato, apto a fazer o que aprendeu na faculdade para que, em seguida, seus alunos assim também o façam igual ao professor, como diria Saviani (1995, p. 15), “[...] para a pedagogia tecnicista o que importa é aprender a fazer”. O problema da pedagogia tecnicista é que há um nítido alinhamento com a produção, eficiência e a adequação ao trabalho, e ao tratarmos especificamente sobre educação física escolar há de se levar em conta aspectos como a exposição corporal, a desvalorização da disciplina em detrimento das intituladas "mais importantes" e o consequente desinteresse dos alunos. Para Saviani (1995, p. 15-16),

Marginalizado será o incompetente (no sentido técnico da palavra), isto é, o ineficiente e improdutivo. A educação estará contribuindo para superar o problema da marginalidade na medida em que formar indivíduos eficientes, portanto, capazes de darem sua parcela de contribuição para o aumento da produtividade da sociedade. 
Ao adotar esse tecnicismo de que fala Saviani (1995), as ementas das cadeiras de esportes na graduação em educação física/licenciatura deveriam levar em conta, além dos aspectos citados no parágrafo anterior, a questão da inclusão social dos alunos da escola pública - setor que ainda atrai boa parte dos profissionais dessa área - principalmente relativa à Educação Física Escolar, pois esses alunos costumam viver em comunidades tão carentes que, às vezes, a aula de Educação Física significa basicamente um ambiente para o aluno fazer o que quiser - e esse momento pode ser único dentro de seu cotidiano. Para o aluno, o que realmente importa é ele ter uma vivência da prática esportiva: "jogar bola" e, preferencialmente, sem a interferência do professor.

Nesse sentido, o professor recém-formado provavelmente encontrará dificuldades em ministrar seu conteúdo puramente tecnicista aprendido na universidade, pois irá se deparar com turmas extremamente heterogêneas e com anseios bem diferentes dos quais o professor poderia imaginar, isso poderá acarretar em um precoce embate na relação professor/ aluno, podendo possivelmente gerar frustrações mútuas... o que de certa forma corrobora com a fala de Saviani (1995, p. 16), a respeito da chamada pedagogia tecnicista:

$[\ldots]$ a pedagogia tecnicista acabou por contribuir para aumentar o caos no cam-
po educativo gerando tal nível de descontinuidade, de heterogeneidade e de
fragmentação, que praticamente inviabiliza o trabalho pedagógico. Com isto
o problema da marginalidade só tendeu a se agravar: o conteúdo do ensino
tornou-se ainda mais rarefeito e a relativa ampliação das vagas se tornou irrele-
vante em face dos altos índices de evasão e repetência.

Percebe-se que uma tendência pedagógica possivelmente estará fadada ao fracasso na medida em que ela se aproximar de uma extrema objetividade, eficiência e produtividade em detrimento de uma abordagem que prioriza a relação professor/aluno, os aspectos inclusivos e a subjetividade que é inerente ao ser humano.

Provavelmente, há uma semelhança palpável entre os ditos tecnicismo/tarefismo e o que Formosinho (2009) denomina de "academização". Esse autor trata como sendo simplesmente uma lógica, aparentemente acadêmica, de característica não flexível e sem interação com a comunidade para onde a futura formação profissional irá atuar e contribuir. Essa lógica acadêmica proporciona então uma progressiva subordinação dos cursos de formação profissional a si própria, e isso talvez seja o que mais se relacione com o tarefismo, no sentido de não haver uma contextualização curricular e um relevante diálogo entre a comunidade escolar e a universidade, pois muitos professores recém-formados, tão logo seu vínculo universitário seja finalizado, já iniciam sua vida profissional em uma escola.

Nesse sentido, se percebe a importância desse contato anterior com o educandário, em que certamente serão vivenciadas experiências valiosas na tentativa de suceder uma possível adequação, adaptação e até mesmo complementação curricular a partir de temas transversais como suplemento dos conteúdos esportivos trabalhados, muitas vezes de maneira puramente tecnicista, nas aulas de educação física no Ensino Médio e Fundamental. Nessa perspectiva, Formosinho (IBIDEM, p. 21) aponta para alguns importantes benefícios 
de uma formação de profissionais de desenvolvimento humano, como a de professores, em uma universidade que adote a lógica profissionalizante em sua formação:

[...] houve múltiplos benefícios para o estudo aplicado das problemáticas reais: mais pesquisa sobre os profissionais de desenvolvimento humano e os seus contextos de trabalho, o alargamento das perspectivas destes profissionais, a emergência de projetos de intervenção e pesquisa-ação e uma maior aproximação da universidade às realidades sociais e profissionais.

É bem nítida e esclarecedora a forma como o autor relata o assunto em questão, deixando claro ser salutar uma apropriação acadêmica (não a academização) de uma lógica profissionalizante, no sentido de existir uma aproximação entre as realidades sociais/profissionais e a universidade, sem deixar de se levar em conta também o contexto de trabalho do futuro profissional. Já no que se refere ao lazer, entendemos que também há um mesmo posicionamento, no entanto, se faz necessária uma maior ênfase no sentido de que haja uma ruptura com o tecnicismo e tarefismo que, tende a confinar o futuro profissional em um técnico, reduzir o papel reflexivo e filosófico deste em todos os seus segmentos de atuação, além de contribuir para a tradição do tarefismo/prático (ancorado em receitas de atividades) da área, que acaba por atrapalhar a oportunidade de se ter uma formação profissional diferenciada com um embasamento teórico sólido (ISAYAMA, 2010, p. 13). Para o autor:

A formação profissional no campo do lazer deve, portanto, ser pautada na competência técnica, científica, política, filosófica, e pedagógica e no conhecimento crítico da realidade. É preciso romper com a visão essencialmente tecnicista, comum em nosso meio, tendo em vista uma práxis consciente.

Percebe-se que o autor aponta para uma formação mais integralizada, não na intenção de que a pura prática deva ser minimizada, mas sim agregada com outras competências como as citadas. $\mathrm{O}$ referido autor ainda faz uma crítica e aponta certo paradoxo vivido nessa temática onde, ao mesmo tempo em que se percebe o aumento da produção científica da área, alguns dos cursos de graduação que ofertam essa disciplina em seus currículos, ainda o fazem de maneira muito restrita e com o mesmo problema de sempre: tarefismo/ tecnicismo, a prática por si só em detrimento de uma reflexão filosófica, sociológica, cultural e política; assim ele salienta que, mesmo com o aumento na discussão sobre o lazer em outros cursos de graduação além da Educação Física, por exemplo Administração, Artes, Turismo, Hotelaria, Pedagogia, Terapia Ocupacional, Fisioterapia e Sociologia:

[...] a análise de muitos desses currículos demonstra que a discussão dos conhecimentos sobre o lazer tem pequeno espaço no interior das propostas. Isso exige a formulação de novas propostas curriculares que possam suscitar um redimensionamento do lazer [...] (IBIDEM, p. 19). 
Nesse sentido, seria admissível que a formação do profissional da área das humanidades - não somente da Educação Física - licenciatura, mas também dos mais diversos cursos como alguns aqui já citados, fosse literalmente passada a limpo na intenção de que possa haver um rompimento com o tecnicismo e a tradição prática, possibilitando uma maior coesão nas ementas das disciplinas ofertadas. Contudo, ao analisarmos com maior especificidade a formação de profissionais de desenvolvimento humano, é pertinente destacar que nesta dificilmente a neutralidade irá se apresentar como uma de suas características, como ressalta Cunha (2004, p. 2):

Se a concepção de formação não é neutra, característica de todo e qualquer ato humano, é preciso analisá-la numa perspectiva que se afaste da concepção meramente técnica. Inclusive, é importante lembrar, que a pesquisa sobre formação de professores pressupõe a não neutralidade.

A autora chama a atenção para o "ato humano" que caracteriza a não neutralidade na concepção de formação de professores e, que dessa forma, deve-se levar em conta a necessidade de que a mesma se distancie de uma concepção puramente técnica; nesse sentido poderíamos estar relacionando novamente aqui a questão da pedagogia tecnicista, tendo como resultado de análise a importância de haver uma identificação da característica humanística no processo de formação e que esta deve se dissociar da concepção de formação meramente técnica.

Se pararmos para refletir um pouco sobre a prática e a teoria, possivelmente chegaremos à conclusão de que uma não pode existir sem que também haja a outra, ou seja, são dependentes e como na fala de Cunha (1988, p. 86): “[...] são duas faces inseparáveis do mesmo ato de conhecer. É dos desafios da prática que nasce o conhecimento teórico, pois é da observação e da experimentação que se desenvolvem a reflexão e a análise". No entanto, a prática de que estamos falando aqui tem como característica o fato de encerrar-se em si mesma, e ainda que esta venha precedida de uma concepção teórica implícita, não se pode dizer que ela seja suficiente para dispensar ou substituir um trabalho de reflexões teóricas em sala de aula, onde existe também a oportunidade de realizar uma profunda análise sociológica, filosófica, política e cultural da temática desenvolvida. Mas o fato é que, seria extremamente importante que não houvesse um distanciamento não só da prática não reflexiva em relação à teoria, mas também da teoria em relação à prática. Para Marcellino (2010, p. 73), por conta da defasagem histórica entre a prática profissional, o ensino e a pesquisa - que ainda existe na área de Educação Física, a ação profissional: "continua desvinculando prática de teoria, o que resulta numa falsa dicotomia, entendendo a primeira como tarefa e a segunda como discurso vazio". Esse é o tarefismo de que estamos falando, nele o professor transporta essa "bagagem" absorvida na universidade até o seu campo de trabalho, e a partir daí começam a aparecer vários equívocos como esses citados pelo autor. $\mathrm{Na}$ verdade, o fato da área da Educação Física ser historicamente ligada a atividades "práticas" propicia um entendimento errôneo de oposição entre a prática e a teoria.

No entanto, é oportuno falarmos aqui dos avanços significativos da área, principalmente no que se refere ao incremento da produção científica, à criação de grupos de pes-

Comunicações $\mid$ Piracicaba $\mid$ v. $26 \mid$ n. $1 \mid$ p. 297-308 $\mid$ jan.-abr. 2019 
quisa em lazer, práticas corporais e cultura em algumas universidades públicas e também privadas. Isso veio a incorporar novas propostas curriculares e também atualizar as ementas disciplinares em alguns cursos de graduação em Educação Física como na Universidade Estadual de Montes Claros-MG, Instituto Federal de Educação Ciência e Tecnologia do Sul de Minas - Campus Muzambinho, por exemplo, onde foi extinta a disciplina de recreação I e II e criada a cadeira de teoria do lazer I e II, e fundamentos do lazer. É relevante destacar esses exemplos de revisão curricular pela qual ainda vem passando esse campo, nesse sentido, Isayama (2010, p. 10) destaca que:

Este incremento na produção sobre o lazer contribuiu de forma significativa para a ampliação das ações no âmbito da formação profissional em nosso país, principalmente no que se refere ao desenvolvimento de cursos centrados no "fazer por fazer", em receitas de atividades ditas "recreativas".

Como vimos demonstrando por meio de alguns exemplos, aponta-se aqui também para o rompimento necessário com a velha prática constituída com fim em si mesma, desprovida de reflexão e que, ao invés de formar profissionais completos e conscientes de sua ação, tende a criar genuínos operadores de manuais de recreação. Essa ruptura certamente proporcionará o desenvolvimento de que fala o autor, no sentido de que possa haver maior qualidade na proposta pedagógica curricular dos cursos de graduação em Educação Física - licenciatura e também bacharelado. Apesar disso, é fundamental deixar claro que entendemos a relevância das práticas corporais originárias das mais diversificadas culturas e que foram espalhadas pelo Brasil, mas na verdade a análise que fazemos aqui é na intenção de que tais práticas sejam problematizadas e que a partir daí possam surgir novas pesquisas que venham estar efetivamente contribuindo com o conhecimento acadêmico.

Seguindo essa linha de raciocínio, tanto o professor como o aluno da universidade deveriam estar a todo momento em prontidão investigativa, pois se sabe que não pode haver conhecimento sem que haja produção do mesmo. Nesse sentido, para Severino (2008, p. 13):

[...] a aprendizagem, à docência, a ensinagem, só serão significativas se forem sustentadas por uma permanente atividade de construção do conhecimento. Tanto quanto o aluno, o professor precisa da pesquisa para bem conduzir um ensino eficaz. [...] praticar a docência mediante uma postura investigativa.

A citação desse autor nos mostra a importância de que exista uma regularidade teórica na aprendizagem, o que propiciará uma consequente formação acadêmica de qualidade com base epistemológica apoiada nas diferentes ciências; a partir de então, compreendemos ser um início para que aconteça uma dissociação mais efetiva entre o tarefismo/tecnicismo e as disciplinas de lazer com seus conteúdos físico-esportivos (esporte, dança, luta, jogo etc.). Essa progressiva mudança na ideologia curricular no campo de esportes e lazer dentro do próprio meio acadêmico pode ser também a chave para uma possível mudança no que o senso comum compreende hoje por Educação Física, esporte e lazer como sendo atividades superficiais, desprovidas de cientificidade e que não há necessidade de se "formar" e estudar para isso. 
Outro problema que pode ocorrer nos cursos de formação profissional em Educação Física é a ausência de interdisciplinaridade entre as disciplinas da performance/biodinâmica e as que envolvem a sociologia das práticas corporais, os aspectos culturais e antropológicos do lazer, reforçando o embate entre as ciências biológicas e as humanidades. Nessa linha, Severino (2008, p. 15) alerta que:

[...] todas as disciplinas do curso devem se articular, fazendo que ocorra envolvimento de todos os docentes. É necessária uma atitude coletiva convergente em termos de exigência de padrão de produção acadêmica.

Ora, é óbvio que em todas as áreas do conhecimento e seus segmentos o diálogo é de fundamental importância e, nesse caso, torna-se determinante para que exista uma produção acadêmica de qualidade, como na fala de Severino (2008), pois é a partir dela que irão surgir os conhecimentos científicos tão necessários para a área.

Além disso, por mais que existam complexidades, divergências teóricas e o embate entre as ciências que servem de base para a Educação Física, é necessário que haja um engajamento incessante na busca de aproximações entre as mesmas com o intuito de promover a qualidade da formação dos futuros professores que também terão o ofício de saber lidar com o desenvolvimento humano. Seguindo essa linha de raciocínio, Sobrinho (2008, p. 194) aponta que:

A educação superior cumpre atividades que carregam significados bastante complexos, relacionados com as questões epistêmicas, éticas, políticas, sociais, econômicas, culturais etc. Entretanto, essa complexidade não deve ser vista como um empobrecimento por fragmentação e, sim, como possibilidade de múltiplas interatuações e relações.

O autor entende que, apesar das inúmeras dificuldades enfrentadas, a educação superior deve ter como uma de suas finalidades o cumprimento das atividades ditas complexas, e estas não devem ser encaradas como um declínio por fragmentação e, sim, com a viabilidade de algumas aproximações. Entendemos que é isso que se espera que aconteça dentro dos cursos de graduação em Educação Física nas diversas universidades espalhadas pelo país, pois diante do incremento da produção científica de temas relacionados às disciplinas de lazer e esporte escolar, e também com o surgimento de muitos grupos de pesquisa que tratam a temática, não existe mais um motivo - se é que havia - para a continuidade desse distanciamento entre as duas vertentes da área, principalmente no interior de muitos cursos de pós-graduação onde se costuma haver uma divisão das linhas de pesquisa, sem a devida precaução com relação aos aspectos das aproximações ou as interatuações e relações de que fala Sobrinho (2008).

\section{CONSIDERAÇões FINAIS}

Vimos que, de fato o tecnicismo e o tarefismo se apresentam como problemas a serem enfrentados não só pela graduação dos cursos de Educação Física das universidades que

Comunicações $\mid$ Piracicaba $\mid$ v. $26 \mid$ n. $1 \mid$ p. 297-308 | jan.-abr. 2019 
ofertam as disciplinas de lazer e esporte escolar, mas também isso acaba se estendendo aos programas de pós-graduação, o que tende a complicar ainda mais a situação, pois esse é o local onde justamente deveria haver uma maior aproximação e diálogo entre as duas vertentes da Educação Física, seja o da performance/biodinâmica seja a parte da pedagogia do movimento, lazer e aspectos sociais e culturais esportivos, no sentido de que esses programas formem mestres e doutores com uma visão mais ampliada das disciplinas em questão e, por conseguinte, possam proporcionar mudanças positivas nas ementas disciplinares e curriculares dos cursos de graduação que possivelmente irão atuar.

As mudanças que entendemos serem necessárias estão situadas principalmente num tecnicismo e tarefismo demasiados e desprovidos de reflexão, interações e proximidades com os aspectos sociais, filosóficos, culturais e pedagógicos, estando limitados a atividades puramente práticas de manuais que já vêm prontos. Sendo assim, a ação se transforma em um "fazer por fazer" sem muito sentido, o que é perigoso ao corroborar com o entendimento do senso comum de que qualquer um pode desenvolver essas atividades sem que seja necessária a formação superior. Mas é necessário deixar claro que, entendemos a relevância das práticas corporais originárias das mais diversificadas culturas e que foram espalhadas pelo Brasil, e a crítica é direcionada, na verdade, a esse modelo que tem origens históricas profundas nas tradições militares e higienistas da área de Educação Física, ressaltamos também a participação de ex-atletas sem a devida formação pedagógica dentro do ambiente escolar e comunitário.

Por sua vez, a crítica que se faz está mais direcionada ao que acontece dentro dos próprios cursos de formação profissional em Educação Física, onde o acadêmico, ao ingressar na faculdade, já se depara com essa conjuntura equivocada e assim tenderá a reproduzi-la na futura vida profissional que terá pela frente. Mas entendemos que há possibilidades tanto para os novos discentes quanto para os profissionais que já atuam nessa área, um exemplo disso pode ser a proposição do diálogo entre a universidade e a comunidade por meio da extensão, ou também democratizar o acesso da comunidade à escola nos finais de semana com momentos culturais e esportivos, como na pedagogia da animação de que fala Marcellino (1987).

Entretanto, o mais importante aqui é registrar que houve avanços como o incremento da produção científica dos temas ligados ao esporte escolar, lazer, práticas corporais e cultura, e também de grupos de pesquisa que tratam a temática, o que tende a contribuir de maneira positiva na ruptura puramente prática e tecnicista, no entanto, há necessidade de maiores avanços, sobretudo na visão de dicotomia entre prática e teoria - entendendo a prática como "tarefas" e teoria como um "discurso vazio" - dos próprios profissionais que tiveram a formação tecnicista e que ainda pendem a resistir às transformações pelas quais vêm passando a área.

Nesse sentido, torna-se importante a proposta da realização de simpósios e colóquios, cuja temática esteja centrada no diálogo entre as mencionadas vertentes da área no sentido de que haja mais respaldo científico para a discussão e que surjam não receitas prontas, como no próprio tarefismo, mas caminhos possíveis de serem seguidos. 


\section{REFERÊNCIAS}

CUNHA, M. I. Diferentes Olhares Sobre as Práticas Pedagógicas no Ensino Superior: A docência e a sua formação. Revista Educação, Porto Alegre ano XXVII, n. 3 (54), p. 525-536, set./dez. 2004.

DUMAZEDIER, J. Valores e Conteúdos Culturais do Lazer. São Paulo: SESC, 1980.

FERREIRA et al. Lazer e cultura: a atuação do profissional de educação física. Licere, Belo Horizonte, v. 16, n. 2, p. 1-19, 2013.

FORMOSINHO, J. Dilemas e tensões da atuação da universidade frente à formação de profissionais de desenvolvimento humano. São Paulo: USP, 2008.

ISAYAMA, H. F. Lazer em Estudo: Currículo e Formação Profissional. Campinas: Papirus, 2010.

MARCELLINO, N. C. Formação Profissional em Lazer e Educação Física. In: ISAYAMA, H. F. Lazer em Estudo: Currículo e Formação Profissional. Campinas: Papirus, 2010.

SAVIANI, D. Escola e Democracia: teorias da educação, curvatura da vara, onze teses sobre educação e política, 4. ed. Campinas: Autores Associados, 1995.

SEVERINO, A. J. Ensino e Pesquisa na Docência Universitária: Caminhos para integração: São Paulo: USP, 2008.

SOARES, C. L. Educação Física: raízes europeias e Brasil. Campinas, SP: Autores Associados, 1994.

SOBRINHO, J. D. Avaliação Educativa: produção de sentidos com valor de formação. Avaliação, Campinas, Sorocaba SP, v. 13, n. 1, p. 193-207, mar. 2008.

\section{Dados do autor:}

Marcelo de Farias Teixeira

Mestrando em Ciências do Movimento Humano na Universidade Metodista de Piracicaba. Professor de Educação Física no Instituto Federal do Norte de Minas Gerais, Campus Januária. Januária/MG - Brasil. marcellofat@,bol.com.br

Submetido em: 27-10-2018

Aceito em: $12-4-2019$ 